\title{
Possibilities for Passives in Natural and Artificial Languages
}

\author{
Christo Moskovsky \& Alan Libert \\ University of Newcastle
}

\begin{abstract}
The Passive Voice is a category which we find in the large majority of natural languages, and also in most artificial languages. The first major part of this paper offers a survey of passive constructions in a number of typologically distinct natural languages, with the basic aim of presenting the (prospective) artificial language constructor with the range of functional and formal properties of the Passive Voice which occur in natural languages. This survey shows that regardless of the fair amount of variation in the morphosyntactic form of passives that we find in different natural languages, crosslinguistically passives are remarkably uniform in inevitably occurring as a grammatical category marked (synthetically or analytically) on the verb; they are also remarkably uniform in relation to the basic function they perform: passivization inevitably involves demotion of a primary clausal term (the Subject) and in most of the cases also promotion of a non-primary term. The next part of the paper offers an overview of Passive Voice formation and function in artificial languages, which will provide the language constructor with a good idea of some of the 'design' decisions taken with regard to this grammatical category. Finally, the paper briefly discusses various design issues in relation to economy, explicitness/ambiguity,
\end{abstract}


102 Possibilities for Passives in Natural and Artificial Languages

functionality, and learnability and presents some specific recommendations with regard to the possible design of passives in an artificial language.

Keywords: passive, voice, verb, morphology, syntax, artificial language

\section{Introduction}

Constructors of artificial languages (ALs) face a number of interesting and potentially challenging design problems. ${ }^{1}$ However, before specific problems (relating, e.g., to structural, functional, meaningful, etc. aspects of the language under construction) are dealt with, the AL constructor must address one very fundamental question: should the language he is involved in designing be modelled on natural language? We believe that there are at least two valid reasons why it should: one is conceptual-philosophical, the second is cognitive. In relation to the former, natural language is, universally, the only comprehensive system for communication

\footnotetext{
${ }^{1} \mathrm{We}$ use the following abbreviations in glosses of examples:

$\begin{array}{lll}\text { ABL }- \text { ablative } & \text { DO - direct object } & \text { PART - participle } \\ \text { ABS - absolutive } & \text { ERG - ergative } & \text { PASS - passive } \\ \text { ACC - accusative } & \text { GEN - genitive } & \text { PL - plural } \\ \text { ACT - actor } & \text { IMPERS - impersonal } & \text { PREP - preposition } \\ \text { AL - artificial language } & \text { INF - infinitive } & \text { PRES - present } \\ \text { ANTIPASS - antipassive } & \text { INSTR - instrumental } & \text { PST - past } \\ \text { AOR - aorist } & \text { IO - indirect object } & \text { PSTPART - past participle } \\ \text { ART - article } & \text { IMPERF-imperfect } & \text { PV - passive voice } \\ \text { ASP - aspect } & \text { NOM - nominative } & \text { REFL - reflexive pronoun or clitic } \\ \text { AUX - auxiliary verb } & \text { OPrep - object of preposition } & \text { SG - singular } \\ \text { CIRC - circumstantial } & \text { PART - participle } & \text { SU - subject } \\ \text { CL - clitic } & \text { PERF - perfect } & \text { TOP - topic }\end{array}$

DAT - dative

Also, "OT" indicates that a translation is by us, rather than being made by the source. We have sometimes not indicated the internal structure of words where this was not relevant. Sometimes we have left out a translation when the word for word gloss was sufficient for understanding the meaning of the example.
} 
among people: wherever there are people, they use natural language as their principal (and, most of the time, only) means to communicate with each other, and while sometimes there may be, in addition to language, some other non-linguistic symbolic communication system, its communicative potential and the range of conceptual domains in which it is used would be extremely limited. Given the universality of natural language, one almost inevitable conclusion would be that it must be well suited to perform the function of human communication, alongside a range of other important functions, ${ }^{2}$ and that some of its basic properties are likely to be essential to those functions. The issue of learnability should also be of prime concern to the AL constructor: in view of the fact that in most normal circumstances ALs would acquired as a second language, then learners could be expected to cope in a more efficient manner with the learning of a new communication system which bears at least some of the basic properties of a communication system they are already familiar with. ${ }^{3}$

In a series of papers (see Libert \& Moskovsky 2002, 2003), we are considering some of the most common grammatical categories of natural language and how they are represented in a range of natural and artificial languages. ${ }^{4}$ One such grammatical category is the Passive Voice (PV): authors involved in typological studies of natural language (e.g., Keenan 1985, among many others) acknowledge that a distinct (morphological) form associated with (but, often, not only)

\footnotetext{
${ }^{2}$ There is a growing recognition of the key role that language plays in relation to thinking, especially in those (usually conscious) thinking processes which Vygotsky has described as "higher mental functions" (see, e.g., Williams 1989). Some (e.g., Gleitman \& Liberman 1995) have also emphasized the importance of language in relation to the attainment and storage of knowledge (e.g., as a medium of representation for knowledge in the human mind).

${ }^{3}$ It has now been established that (adult) second language learners find it much harder to become proficient in second languages which are typologically distant from their native language (Ringbom 1987). This would suggest that it would be even harder to attain competence in a communication system which is radically different from natural language.

${ }^{4} \mathrm{We}$ exclude from the set of artificial languages fictional languages, such as Klingon
} 
104 Possibilities for Passives in Natural and Artificial Languages

a passive meaning can be found in the vast majority of human languages. Such facts strongly suggest that the PV is an indispensable property of human language.

\section{Natural Languages}

In the most typical case, sentences in PV are analysed as derived from corresponding sentences in the Active Voice, and this derivation minimally involves applying some specialised verbal morphology (often unique to PV) and, frequently, also change in the order of sentence constituents:

(1) $\left\{\mathrm{NP}_{1}-\mathrm{V}-\mathrm{NP}_{2}\right\}_{\text {ACtIVE }} \rightarrow\left\{\mathrm{NP}_{2}-\mathrm{V}-\underline{\mathbf{P A S S}}-\left(\mathrm{NP}_{1}\right)\right\}_{\text {PASSIVE }}$

A suitable example from English to illustrate this is provided in (2):

(2) $\left\{\left[\mathrm{NP}_{1} \text { The Council }\right] \text { - will consider }-\left[\mathrm{NP}_{2} \text { your proposal }\right]\right\}_{\text {ACTIVE }}$ $\rightarrow\left\{\left[\mathrm{NP}_{2}\right.\right.$ Your proposal] - will $\underline{\mathbf{B E}}$ considerED $-\left(\right.$ by $\left[\mathrm{NP}_{1}\right.$ the Council]) $\}_{\text {PASSIVE }}$

PV formation can involve the use of an auxiliary verb (AUX) together with a specific form of the main verb (most commonly, a participle), as in the example above, or only a specific (passive) verbal morpheme, as in the Kinyarwanda example below: ${ }^{5}$

(3)
a. Abagóre
ba-a-boon-ye
mweébwe.
Women
they-PST-see-ASP
you-PL
'The women saw you.'

\footnotetext{
5 In Keenan's (1985) terms, "periphrastic" and "strict morphological" passives, respectively.
} 


\section{b. Mweébwe mw-aa-boon-y-w-en n'âbagóre. you you-PST-see-ASP-PASS-ASP by-women 'You were seen by the women.' (Kimenyi 1988:363)}

In other words, passivization involves derivation of a (morphologically and/or syntactically) marked construction (M) from a (morphologically and/or syntactically) unmarked or neutral construction (Ø) (Comrie 1988): ${ }^{6}$

\section{(4) $\varnothing_{\text {ACTIVE }} \rightarrow M_{\text {PASSIVE }}$}

Semantically, the basic difference between the active and the passive member of the pairs of sentences above is that the semantic roles associated with the arguments of the verb are differentially aligned with syntactic functions (Huddleston \& Pullum 2002:1427): in the passive sentences, the subjects (SUs) are associated with the semantic role of the direct objects (DOs) of the corresponding active sentence, while SUs of the active sentences take up an oblique syntactic function in the passive equivalent (or are eliminated altogether).

It is widely agreed that one of the most typical discourse functions of passivization is change of the thematic focus in the sentence: from the entity denoted by SU NP in the active sentence to the entity denoted by Object NP (and, perhaps, in part to the action denoted by the verb). This change of thematic focus is commonly accomplished by way of promoting one of the arguments of the verb and demoting, or even completely eliminating, another argument (Keenan 1985, Palmer 1994).

Change of thematic focus and/or promotion of an argument is by far not specific to passive constructions (as in (5b)): we also find it in

\footnotetext{
${ }^{6}$ But note our example (14) from Tagalog which probably represents a type of language in which Active and Passive Voice are equally marked.
} 
106 Possibilities for Passives in Natural and Artificial Languages

other derived constructions such as (5c) and (5d) which literature commonly defines as cases of "topicalization" and "left-dislocation", respectively:

(5) a. The Council will consider your proposal next week. (active)

b. Your proposal will be considered by the Council next week. (passive)

c. Your proposal the Council will consider __ next week. (topicalization)

d. As for your proposal, the Council will consider it next week. (left dislocation)

The most obvious formal difference between $(5 b)$ and $(5 c, d)$ is that $(5 b)$ involves a morphological marking on the verb which is specific to PV, while sentences such as $(5 \mathrm{c}, \mathrm{d})$ don't; in other words, the verb in constructions like $(5 \mathrm{c}, \mathrm{d})$ remains unchanged, i.e. in its basic unmarked active form. Another significant difference can be observed in relation to the grammatical function of the promoted constituent: passivization involves a change of grammatical function, while topicalization does not. There are a range of other important differences. As Keenan (1985:244, among others) has noted, in cases of topicalization the promoted constituent occupies a sentence position which is "unusual" and is specifically created (e.g., by way of adjunction) for that purpose, while in passivization the promoted constituent takes up one of the basic sentence positions, that of the Subject. Significantly, the promoted constituent then assumes all the properties (e.g., morphological, syntactic, discourse, etc.) typically associated with subjects. ${ }^{7}$ One of the consequences of this is that a

\footnotetext{
${ }^{7}$ E.g., the ability to operate as a syntactic and/or pragmatic pivot, to operate as an antecedent in an anaphoric relationship, etc. The reader should bear in mind that the SU NP is, syntactically, in many ways unique: it is the only structural node in the
} 
non-SU constituent in the active sentence becomes a $\mathrm{SU}$ in the passive equivalent, and it acquires the higher thematic status that sentence subjects have by virtue of their position. However, this thematic status is in no way exceptional and is definitely less prominent than the thematic status of a topicalized constituent: in this sense, thematically the NP your proposal is much more of a topic in topicalized constructions like (5c) than in PV constructions like (5b). Keenan also suggests that PV must be a much more fundamental grammatical category than topicalization or left-dislocation, because while it is possible to conduct all major syntactic operations, such as nominalization, question formation, relative clause formation, etc., on PV constructions, there are severe restrictions on the types of syntactic operations that can be conducted on topicalized or left-dislocated constructions. Furthermore, as Palmer (1995) has pointed out, in passivization the promoted constituent is most commonly an argument $\mathrm{NP}^{8}$, while topicalization can involve practically any syntactic constituent.

Another issue that needs to be addressed with regard to the scope of the grammatical category of PV is the distinction between "true" $\mathrm{PV}$ and "stative" $\mathrm{PV}^{9}$. This distinction is most obvious in languages which have two different morphological forms for the two types of $\mathrm{PV}$, as is the case in German:

$\begin{array}{rlll}\text { (6) a. Der Tisch } & \text { wird } & \text { gedeckt. ('true passive } \\ \text { the } & \text { table } & \text { becomes } \\ \text { covered }\end{array}$

'The table is being laid.'

clause which c-commands all other nodes in the same clause, but is not c-commanded by another node.

${ }^{8}$ This could be argued to hold even for sentences such as (i), in which the preposition in is reanalyzed with the verb.:

(i) This bed has not been slept in.

${ }^{9}$ The terms verbal and adjectival passive are also commonly used in literature.

${ }^{10}$ The respective German terms are Vorgangspassive and Zustandspassive. 
108 Possibilities for Passives in Natural and Artificial Languages

b. Der Tisch ist $\quad$ gedeckt. ('stative passive' ${ }^{10}$ )
the table is
covered

Nedjalkov \& Jaxontov (1988:47) discuss another interesting example (originally in Jespersen 1924:274) which is particularly illustrative of the difference between 'stative' and 'true' PV:

(7) Als ich um fünf kam, war die Tür geschlossen, when I at five came was the door locked aber ich weiß nicht, wann sie geschlossen wurde. but I know not when it locked became 'When I came (home) at five, the door was locked but I don't know when it was locked.'

As these examples show, in German different auxiliary verbs are used with the two types of PV: werden 'become' and sein 'be'. German reference grammars describe the grammatical construction in (6a) as a passive voice expressing an action, and the grammatical construction in (6b) as a passive voice expressing a state. In languages like English which generally use one AUX for the formation of PV (and which seems to be the more common case crosslinguistically), certain sentences can potentially yield both 'stative' and 'true' PV interpretation:

(8) The house was deserted.

This sentence can be interpreted as a statement about a specific property ("deserted") that a house has, which would be the 'stative' interpretation; alternatively, it can be interpreted as a statement about the occurrence of an event involving the house (i.e., that its occupants left it), which would be the 'true passive' interpretation. It seems that the two different interpretations are derived from the ambiguous 
categorial status of past participles, which can be used as (main) verbs and also as adjectives: when the participle is used as a form of the verb, then the 'true passive' interpretation is derived; when the participle is used as an adjective, we get the 'stative' interpretation. With regard to the latter, it is unclear in what ways sentences such as (8) differ from sentences with a copular verb and a predicative adjective:

(9) The house was big.

In both cases they perform the grammatical function of Subject-complement, and in both cases we can use the predicative adjective attributively:

(10) a. the big house

b. the deserted house

In the light of this, it does not really seem justified to treat 'stative' passives as a genuine case of PV, and therefore, they will not be considered in this paper. Another construction (see (11)), which is sometimes described as "Middle Voice", will also be ignored here:

\section{(11) The door opened.}

While semantically there may be good reasons to describe (11) in different terms from a sentence like My aunt arrived, in the strictly formal approach adopted here both can only be analysed as intransitive sentences in the active voice.

Before we complete these brief introductory notes, a few words about the notion of 'antipassive' are in order. Constructions referred to with the term 'antipassive' are normally found in ErgativeAbsolutive (ERG-ABS) languages; in a number of aspects, such constructions can be treated as a mirror image of PV constructions in Nominative-Accusative (NOM-ACC) languages. Within the latter, in 
110 Possibilities for Passives in Natural and Artificial Languages

the 'core' unmarked (i.e., active) clause, the primary term is normally marked for the NOM and can loosely be described as ACTOR (or the entity involved in enacting the verbal action); the term loosely denoting the PATIENT (or the entity being acted on) would usually (but not always) take ACC marking; in clauses involving a single term (i.e., intransitive clauses), the primary term is the NOM SU. In these languages, passivization involves promoting a non-primary term to SU position and demoting a primary term to a position with a peripheral, e.g., oblique, status (see (2-3)). In contrast, in the typical 'core' unmarked clause in an ERG-ABS language the primary term is normally marked for ABS and can loosely be described as denoting the PATIENT (or the entity being acted on), while the ACTOR would normally be marked for ERG (see (12a) below); in clauses involving a single term (i.e., intransitive clauses), the primary term is the ABS SU. In the corresponding 'antipassive' construction, the non-primary term (the ACTOR) is promoted to SU position and is accordingly marked for ABS, while the primary term of the active sentence (the PATIENT) is demoted to a peripheral (oblique) position and is marked for a different morphological case: Dative (DAT) in this case:

(12) Yidin (Australia)
a. Wagudya-ngu man-ERG
bunya- $\varnothing$
giba:1.
'The man scratched the woman.'
b. Wagu:dya-ø man-ABS
giba-:dyi-nyu bunya:-nda. scratch-ANTIPASS-PST woman-DAT 'The man scratched the woman.' (Dixon 1977, cited in Foley \& van Valin 1985:338)

Even though the promotion/demotion of terms taking place in 'antipassive' constructions like (12b) above goes, as far as the ACTOR-PATIENT dichotomy is concerned, in the opposite direction than the promotion/demotion of terms in typically PV constructions, 
the phenomenon is essentially the same: a primary term is demoted and a non-primary term is promoted. ${ }^{11}$ In light of this, there does not seem to be a valid reason to treat 'antipassive' constructions differently from standard PV. Within such an approach, one relevant question is whether we should go as far as calling them "passive" (as suggested by Palmer 1994:158). The view taken here is that the term 'antipassive' should be preserved, because it appears to capture the essence of these constructions: 'antipassivization' in ERG-ABS languages seems to involve exactly what occurs when a NOM-ACC $\mathrm{PV}$ construction is converted into a corresponding active construction, i.e. an ACTOR/AGENT is promoted and a PATIENT is demoted. In this regard, the term 'antipassive' appears to be very appropriate. Another solid reason why the term 'antipassive' should be preserved is to distinguish constructions like (12b) above from what seem to be typically PV constructions like (13b), which we also find in ERG-ABS languages (sometimes in the same language alongside 'antipassive' constructions):

(13) Tzotzil (Mayan, Mexico)

a. S-mil-ox- $\varnothing \quad$ Xan li Petal e. 3SG(ERG)-kill-PST-3SG(ABS) John DET Peter 'Peter killed John.'

b. Mil-bil-ø yu?un Petal li Xan e. kill-PASS-3SG(ABS) by Peter DET John 'John was killed by Peter.' (Foley \& van Valin 1985:312)

In the following two sections, we shall consider formal and functional aspects of the typology of PV constructions in natural language, and then in the second part of this paper we shall present an overview of PV constructions in a range of artificial languages (ALs).

\footnotetext{
${ }^{11}$ Other terms frequently used in the same sense are 'foregrounding' and 'backgrounding', respectively.
} 
112 Possibilities for Passives in Natural and Artificial Languages

\subsection{Typology of Passive Voice Formation in Natural Languages}

As can be expected, there is a substantial amount of variety in relation to how different natural languages form their $\mathrm{PV}$ constructions, which sentence positions (e.g., DO, IO, OPrep, Adverbial, etc.) can undergo passivization, and the range of functions that a PV construction can perform. Before these issues are briefly discussed below, it is important to note that there are at least two aspects in which PV constructions are, crosslinguistically, remarkably uniform: PV is invariably a formal feature of the verb phrase, and it invariably involves demotion of a 'core' term (or argument): most commonly the clausal subject. Also, in all (but one) of the natural languages that we have reviewed for the purposes of this paper, we find the characteristic dichotomy between an unmarked Active Voice and a marked Passive Voice construction (see (4) above); the only exception we are aware of is Tagalog, in which Active and Passive voice seem to be equally marked:

(14) Tagalog

a. S[um]ampal ng lalake ang babae. [ACTIVE]-slap DO man TOP woman 'The woman slapped the man.'

b. S[in]ampal ng babae ang lalake. [PASSIVE]-slap ACT woman TOP man 'The man was slapped by the woman.'(Keenan 1985:252)

One typologically important distinction which we already briefly touched upon is between synthetic and analytical PV ('strict morphological' and 'periphrastic' in Keenan's (1985) terms): in the former, PV formation involves a passive morphological marker on the verb as, e.g., in (3), repeated here: 
(3) b. Mweébwe mw-aa-boon-y-w-e-e n'âbagóre. You you-PST-see-ASP-PASS-ASP by-women 'You were seen by the women.'

Another language which uses synthetic PV is Turkish:

(15) Cevap yaz-mak için kâğit-la kalem kullan-il-ir. answer write-INF for paper-and pen use-PASS-PRES 'Paper and pencil may be used to write the answer.' (Shibatani 1985:828, corrected)

It seems that in the vast majority of languages using synthetic PV there is a single passive morphological marker which is used to mark $\mathrm{PV}$, regardless of which clausal term is involved in the passivization (e.g., DO, IO, or something else). We are aware, however, of at least one language which uses different morphological markers for PV constructions involving different clausal terms:

(16) Malagasy

a. Nividy ny vary ho anরny ankizy ny vehivavy. bought-ACT the rice for the children the woman 'The woman bought rice for the childen.'

b. Nividin $\Lambda$ ny vehivavy ho anKny ankizy bought-PASS the woman for the children ny vary. the rice

'The rice was bought by the woman for the children.'

c. Nividianan $\Lambda$ ny vehivavy ny vary ny ankizy. bought-CIRC the woman the rice the children 'The children were bought rice by the woman.'

d. Nividianan $\Lambda$ ny vehivavy ny vary ny vola. bought-CIRC the woman the rice the money 'The money was used to buy rice by the woman.' 
114 Possibilities for Passives in Natural and Artificial Languages

(Keenan 1972:172-3, cited in Palmer 1994:17)

(16a) is the unmarked active clause from which various PV constructions are derived. (16b) involves the most basic type of PV, in which the DO is promoted to SU position. (16c) and (16d) involve promotion of IO and INSTR, respectively. ${ }^{12}$ The reader will note that the morphological marker used for the passivization of the DO is different from the morphological marker used for the passivization of the IO and the INSTR.

Before we move on to consider the analytical (or 'periphrastic') type of PV construction, we should note that there are languages in which the passive morpheme is also used to express reflexive and middle meaning:

(17) Western Armenian
a. Namag- k r-v-ets-av Mari-e-n. letter-the write- $v$-AOR-3SG Mari-ABL-the 'The letter was written by Mari.'
b. Vartan- hak-v-ets-av. Vartan-the wear- $v$-AOR-3SG
'Vartan dressed (himself).'
c. Tur- kots-v-ets-av. door-the open- $v$-AOR-3SG
'The door opened.' (Haig 1982:162-5)

Such data should not be regarded as very unusual or surprising, given the substantial overlap which we find crosslinguistically between passive, reflexive, impersonal, and middle constructions (briefly discussed below).

As Keenan has noted, while most natural languages would make use of either one or the other, occasionally we find languages using both. Whether one is used or the other can be determined by aspect, as

\footnotetext{
${ }^{12}$ Keenan has described the constructions in $(16 c, d)$ as 'circumstantial' voice.
} 
in the following:

(18) Latin

a. Pugnatur uno tempore fight-3SG-PRES-PASS one-SG-AB time-SG-ABL omnibus locis. all-PL-ABL place-PL-ABL

'There is fighting at one time in all places.'

(Caes. B.G. 7, 84, in Palmer 1994:127)

b. Dareus (ab Alexandro) victus est.

Darius (by Alexander) conquered is

'Darius was conquered (by Alexander).' (Keenan 1985:251)

Most of the European languages are like English with regard to PV formation: it involves a combination of two grammatical elements: an AUX (usually be) and a (participial) form of the main verb. More often than not, these grammatical elements are not specific to PV: for instance, in English, the AUX be is also used to mark Progressive aspect, while the Past Participle is used in the Perfect Aspect. There are languages (e.g., Bulgarian), in which we find two distinct forms of the past participle: one for use in active constructions (e.g., with the perfect aspect) and another strictly for PV constructions:

a. Bashta mu e postroil nov dom. father his-CL is build-PASTPART(ACT) new home 'His father has built a new home.'
b. Nov dom beshe postroen
new home was build-PASTPART(PASS)
(ot bashta mu).
from father his-CL
'A new home was built (by his father).'


Again according to Keenan (1985), PV constructions of the analytical type can be further subdivided into four categories, depending on the type of AUX involved: 1) be/become (see (20a) below, as well as (2) and (6) above); 2) verbs of reception (see (20b) below); 3) verbs of motion (see (20c) below); 4) verbs of experiencing (see (20d) below).

(20) a. Persian

Ahmed košté šod.

Ahmed killed become

'Ahmed was killed.' (Keenan 1985:257-60)

b. Tzeltal

La $y$-ich $\Lambda$ Kutel (yuKun s-tat) te

PST he-receive bawling out because his-father Ziak-e.

ART Ziak-ART

'Ziak got a bawling out (from his father).' (ibid.)

c. $\underline{\text { Hindi }}$

Murgi mari gayee.

chicken killed went

'The chicken was killed.' (ibid.)

d. Vietnamese
Quang bi
(Bao) ghet.
Quang suffer (Bao) detest
'Quang is detested (by Bao).' (ibid.)

It is not uncommon for a language to make use of more than one of these auxiliary verbs. Indeed, this is the case in Persian, where we find both 'become' (as in (20a) above) and 'go' used as a PV auxiliary:

(21) a. Ali loget-ra be kar bord. Ali word-DO to work take 


\section{'Ali used the word.'}

b. Loget be kar reft.
word to work went
'The word was used.' (ibid.)

In English itself, we find the verb 'get' sometimes used to express passive meaning, as in the following example:

(22) Both doctors got reprimanded by the hospital board. (Huddleston \& Pullum 2002:1443)

It appears, however, that this use of 'get' is highly restricted in that there are a range of semantic and pragmatic limitations on it $^{13}$. Also, there is not complete agreement in relation to the actual status of 'get' in these constructions: is it an auxiliary verb or not? Huddleston \& Pullum (ibid.) have argued that constructions like (22) are actually complex sentences consisting of a main clause [Both doctors got $\mathrm{X}]$, which is in the Active voice, and a subordinate complement clause [x PRO reprimanded by the hospital board], which is in the PV. ${ }^{14}$

Our overview will remain incomplete if we fail to discuss the use of reflexive forms (e.g., reflexive clitics) to express passive meaning. In the natural languages we have considered in this paper, marking

\footnotetext{
${ }^{13}$ Huddleston \& Pullum (2002: 1442) note, for instance, that constructions like (22) are only found with what they call 'dynamic verbs'.

${ }^{14}$ Huddleston \& Pullum (2002: 1430) call these 'bare passives'. Here is another example they discuss:
}

The guy [mauled by our neighbour's dog] is in intensive care.

While superficially the bracketed relative clause is incomplete in that it has no overt subject and no AUX, they are recoverable and therefore it is not completely clear whether treating them in terms of "bare passives" is the most appropriate analysis for them. If this analysis is, nevertheless, adopted, then these 'bare' passives would constitute a case of synthetic PV. 
118 Possibilities for Passives in Natural and Artificial Languages

PV with a reflexive form is a very common device, alongside the "true" PV marker (be that 'periphrastic' or 'strict morphological'). The following example from Russian illustrates the two types:

(23)
a. Kalitka byla otkryta gate-NOM was open-PERFECTIVE-PST PART Olegom.
Oleg-INSTR
'The gate was opened by Oleg.'
b. Kalitka otkrylas' Olegom gate-NOM open-IMPERFECTIVE-REFL Oleg-INSTR 'The gate was opened by Oleg.' (Siewerska 1985:247)

Passive-reflexive forms are very common in the Slavic languages:

(24) $\underline{\text { Czech }}$

Zivne latky se pobleuji filtrem.

Nutritive substances REFL absorb-3PL filter-INSTR

'Nutritive substances are absorbed by filter.' (ibid.:246)

(25) Polish

Owe przesądy dzisiaj inaczej się These prejudices-ACC today differently SELF Interpretuje. interpret

'These prejudices are interpreted differently today.' (ibid.:262)

(26) Bulgarian

Vasheto predlozhenie shte se razgleda ot your-the proposal will self-CL consider from saveta.

council-the 
'Your proposal will be considered by the Council.'

We also find passive-reflexive forms in the Romance languages:

(27) Italian

a. $\mathrm{Si}$ comprano duepenne.

REFL buy-3PL twopens

'Two pens are bought.'

b. Questo giornale si legge ogni

This newspaper REFL read-3SG-PRES each

mattina da morning by.

moltissima gente very many people

'This newspaper is read every morning by lots of people.' (Palmer 1994:143)

(28) $\underline{\text { Spanish }}$

Se curó a los brujos.

REFL cured-3SING to the-PL sorcerers-PL

'The sorcerers were cured.' (ibid.:144)

(29) French

La porte s'est ouverte.

the door REFL-is opened

'The door opened.' (ibid.:143)

It should be noted that in the Romance language these forms are more commonly used to express impersonal (e.g., (27a) and (28)) and/or "middle" (e.g., (29)), rather than "true" passive, meaning. In fact, in contrast to Slavic, these languages do not easily permit expression of the agent in passive-reflexive constructions of the type exemplified above, and sentences like the one in (27b) seem to be quite rare. In relation to this, it should also be noted that crosslinguistically there seems to be a substantial overlap among constructions expressing 
120 Possibilities for Passives in Natural and Artificial Languages

passive, reflexive, middle and impersonal meaning (for an extensive discussion of this issue, see, e.g., Shibatani 1985). Interestingly, with all of them the reflexive marker (a pronoun, a clitic or a bound morpheme) performs the same function: it changes the subcategorization frame of the verb by reducing the number of its arguments; as we shall see shortly, this is also one of the most important functions of passivization (according to some, the principal one). ${ }^{15}$

The wide-spread occurrence of passive-reflexive forms in natural languages should not necessarily be seen as very unusual or surprising, given that reflexivity inherently involves a "passive" component: in the most typical case of 'true' reflexivity, the entity denoted by the SU NP initiates and carries out an action which is directed back onto the same entity, making the SU not only an Actor (e.g., Agent or Experiencer), but also a Patient:

(30) John described himself as an honest man.

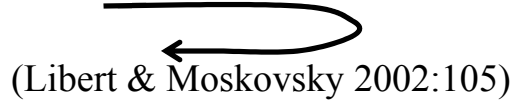

The action denoted by the verb in a reflexive construction can be analysed as consisting of two distinct components: an active and a passive one. Curiously, the device reflexive constructions in some languages employ to convey a strictly passive meaning is to somehow block the active component of the action. For example, in Bulgarian this is accomplished by restricting the semantic category of SUs of passive-reflexive constructions to only inanimate NPs (Maslov 1956): the referent of an inanimate NP SU cannot normally initiate and/or perform an action, and this way only the second (passive)

\footnotetext{
${ }^{15}$ Most commonly, this involves detransitavization of a transitive verb, but can also occur with intransitive verbs, which eliminates the SU Actor, effectively making the sentence impersonal (see below).
} 
component of the reflexive action remains in force ${ }^{16}$ :

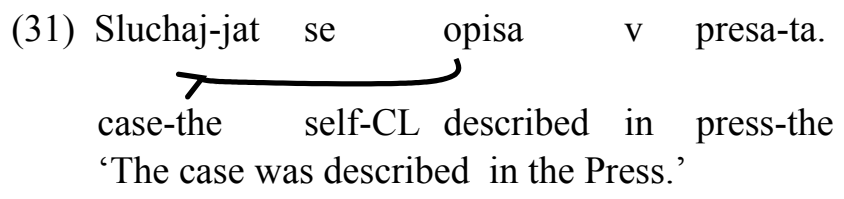

Finally, a brief note about the distribution of passive-reflexive and true passive constructions within the same language. It seems that a semi-complementary relationship holds between the two types of passive: the passive-reflexive type seems to be used almost exclusively with imperfective verbs (or verbs in the imperfective aspect), while true PV can be used with both perfective and imperfective verbs (Nedjalkov \& Jaxontov 1988). Another significant difference between the two is manifested in the fact that non-reflexive PV constructions can have a 'stative' interpretation alongside a 'true passive' interpretation, while passive-reflexive constructions can only have a 'true passive' interpretation.

\subsection{Typology of Passivizable Positions}

In the most common case, the DO NP of the active sentence becomes the SU of the PV sentence while the SU of the active sentence is assigned an oblique (e.g., prepositional) status or is removed altogether, as in (2), repeated here for convenience:

\footnotetext{
${ }^{16}$ There are rare cases in which a reflexive construction with an animate SU can have a strictly passive meaning, but then there are other factors which preclude active participation of the SU in the verbal action, e.g., the semantics of the verb:
}

(i) Toj se rodi $\mathrm{v}$ bogato semejstvo.

$\mathrm{He}$ self-CL bore in rich family

'He was born in a rich family.' 
122 Possibilities for Passives in Natural and Artificial Languages

(2) The Council will consider [your proposal] $]_{\mathrm{DO}} \rightarrow$ [Your proposal $]_{\mathrm{SU}}$ will be considered (by the Council).

In English PV constructions the provision of the Actor/Agent (the SU NP of the active sentence) is optional, however there are many natural languages which do not allow it. The following example is from Latvian, but Keenan (1985:249) lists a number of other languages with the same situation.

$$
\begin{array}{lll}
\text { Es } & \text { tieku } & \text { macits (*no mates) } \\
\text { I } & \text { am } & \text { taught (by mother) (ibid.) }
\end{array}
$$

Keenan also stresses that even in languages which in principle allow the expression of the Actor/Agent in PV constructions, agentless passives are quite often preferred. In view of the fact that one of the main functions of passivization is actually the demotion of the term expressing the Actor/Agent (in NOM-ACC languages), this preference for agentless passives is hardly surprising.

Passivization of positions different from DO (e.g., IO, OPrep, Adverbial, etc.) is possible, but is relatively rare. Among the European languages at least, English seems to be rather exceptional in allowing types of PV constructions like the following:

(33) Bill will be offered an executive position in the company. [IO]

(34) The problem was dealt with very efficiently. [OPrep]

Not surprisingly, such constructions have been subject to extensive research and different analyses have been proposed for their treatment. In relation to sentences like (34), e.g., it has been proposed that the preposition is re-analysed together with the verb, forming a verbal complex $[\mathrm{V}+\mathrm{P}]$, effectively turning the NP into a DO. It is not among the goals of our paper to consider the merit of 
such proposals. What is important for us is that, regardless of the linguistic analysis we adopt, PV constructions of the types exemplified in (33-4) do not exist in most European languages, and are generally rare. This is not to say that languages not allowing PV constructions like (33-4) do not have the potential to promote a non-DO NP: they usually do, but would employ a different mechanism. One way languages can do that is by using an impersonal PV construction:

\section{(35) German}
a. Es
wurde ihm geholfen.
It-IMPERS became him-DAT helped 'He was helped.'
b. Ihm wurde geholfen. Him-DAT became helped 'He was helped.'
c. Gestern wurde ihm geholfen. Yesterday became him-DAT helped 'He was helped yesterday.'

Crosslinguistic evidence indicates that practically any sentence constituent (including temporal and locative nominals) can be promoted (see, e.g., the Malagasy examples in (16) above). Consider the following examples from Kinyarwanda (Kimenyi 1988:361-2):
(36) a. Umugóre y-á-báa-ye perezida. woman she-PST-be-ASP president 'The woman became a president.'
b. Perezida y-á-báa-w-e n'ûmugóre. President he-PST-be-PASS-ASP by woman 'It is the woman that became a president.' (literally: 'A president was become by the woman.')


124 Possibilities for Passives in Natural and Artificial Languages

(37)
$\begin{array}{lll}\text { a. Umagabo } & \text { a-ra-geend-a } & \text { ijoro. } \\ \text { Man } & \text { he-PRES-travel-ASP } & \text { night }\end{array}$
'The man is travelling in the night.'
b. Ijoro ri-ra-geend-w-a
n'ûmugabo.
night it-PRES-travel-PASS-ASP by man
'It is in the night that the man is travelling.'
(literally: 'The night is being travelled in by the man.')

In the first of the examples above, it is the complement NP of a copular verb that undergoes passivization, while in the second example we see a temporal nominal promoted as the SU of the corresponding PV construction. We find another interesting example in Palauan (W. Austronesian) (Foley and van Valin 1985:316-17):

a. a ngelek-ek a sme?er er a tereter. DET child-my sick-INSRT with DET cold 'My child is sick with a cold.'

b. a tereter a l-se?er er ngiy a DET cold PASS+3SG-sick with 3SG DET ngelek-ek. child-my

'With a cold is being sick by my child.'

Even from the more 'permissive' perspective of the English language, these are very unusual examples.

Some natural languages allow for passivization of intransitive active sentences, which does not involve promotion of a non-primary term, but only demotion of the primary term, effectively making the sentence impersonal (also see the Latin example in (18a):

(39) Bulgarian

a. Njakoj e minaval po someone is pass-PSTPART(ACTIVE) along 
tazi pateka skoro.

this trail soon

'Someone has passed long this trail recently.'

b. Minavano e po tazi pateka skoro. pass-PSTPART(PASS) is along this trail soon 'Someone has passed long this trail recently.'

(literally: '(It) has been passed along this trail recently.')

Finally, there are languages like Japanese in which passivization sometimes involves not the promotion of an existing non-primary term, but the creation of a new term; this is the case with the so-called 'adversity passives' (Kuno 1973:23-4, in Palmer 1994:130):

(40)
a. Tuma
ga
sin-da.
wife NOM die-PST
'The wife died.'

b. John ga tuma ni sin-are-ta. John NOM wife by die-PASS-PST

'John was adversely affected by his wife's death.' (literally: 'John was died by his wife.')

\subsection{Typology of Passive Voice Functions}

There is general agreement that syntactically passivization involves promotion of a non-primary term and demotion of a primary term. In fact, some (e.g., Shibatani 1985) have argued that the latter is more fundamental than the former, because some PV constructions may not involve promotion of a non-primary term (as is the case with PV constructions derived from intransitive active sentences (see (39) above)), but all PV constructions involve demotion of a primary term.

As we noted above, passivization typically involves a change in the subcategorization frame of the verb by reducing the number of its arguments. Quite commonly, this is an operation of detransitivizing 
126 Possibilities for Passives in Natural and Artificial Languages

the transitive verb in the active sentence. This is accomplished either by applying passive morphology or by using a reflexive marker (pronoun, clitic, or a morpheme). In fact, there are languages in which a common detransitivizing morpheme is also used as the formative marker for PV:

(41) $\underline{\text { Ainu (Japan) }}$

a. Kamui umma raike.

Bear horse kill

'A bear killed a horse.'

b. Umma kamui orowa a-raike.

horse bear from PASS-kill

'The horse was killed by a bear.' (Shibatani 1985: 824)

As also noted above (see (40) above), in some rare cases passivization involves the creation of a completely new argument, i.e. one which did not exist in the active version.

From a discourse perspective, the promotion of non-primary terms leads to changes in the discourse structure of the sentence: the promoted term acquires a greater thematic focus. Likewise, the demotion of the primary term takes away (some of) its thematic value. As we indicated earlier, in a large number of languages the ACTOR/AGENT associated with the primary term of the active sentence is rarely expressed, or even cannot be expressed at all, in the corresponding PV construction. As many authors have noted (e.g., Jespersen 1924), this makes PV constructions particularly suitable for discourse contexts in which the ACTOR/AGENT is unknown or is unimportant and/or the speaker wishes to focus on the PATIENT (and, perhaps, the verbal action) rather than the ACTOR/AGENT. This is one of the reasons why in many languages PV constructions can yield an impersonal interpretation.

This completes our necessarily brief discussion of PV in natural languages. Next we shall how this grammatical category is 
represented in a range of artificial languages.

\section{Artificial Languages}

We shall discuss only a fraction of the more than a thousand artificial languages which have been created, but this will, we hope, give a general idea of the choices $\mathrm{AL}$ designers have made with respect to the passive. A small number of ALs simply do not have a passive. ${ }^{17}$ For example, Wald (1909) says of pan-kel: "There is no passive"; his example of how it is to be replaced is that I was loved would be expressed by the pan-kel equivalent of One loves me (ibid.). Similarly, concerning frater2 Bartlett (1998) states,

There is no passive construction as such. One may use an impersonal construction with ANTROP as subject, or, if even that will not serve, one may use the null pronoun $\mathbf{K O}$ to indicate that the object receives the action of the verb without specifying any subject or agent. Alternatively, in many cases one may use the reflexive pronoun AFTO to convert an actual or implied passive form: "The book is (found) on the table" becomes BIBLO DONE UREKE AFTO EPI MENSA (literally, "the book confers finding itself on the table").

One might also note that while Unitario does have a passive, the creator of the language states that it "should be avoided" (Pleyer 1990:105).

\footnotetext{
${ }^{17}$ This situation is to be distinguished from that when a full grammar of an AL has not (apparently) been presented and passives are not discussed and do not occur in texts in the language, e.g., Fitusa as described by Rosenblum (1935). For such ALs we cannot know whether there would have been a passive if all the details of the language had been presented. This is again different from the situation when the grammatical description of the AL does not mention passives, but where they occur in texts, as happens in Jones (1972) about Eurolengo. Here we are concerned with ALs for which it is explicitly stated that they do not have a passive.
} 
128 Possibilities for Passives in Natural and Artificial Languages

\subsection{Synthetic and Analytic Passives}

The majority of ALs do have a passive, and we can ask about the general form of it: is it (always) synthetic, (always) analytic, or sometimes synthetic and sometimes analytic, depending on the tense, mood, etc.? A fourth possibility is for an AL to have both synthetic and analytic forms, in free variation.

A fair number of ALs only mark passive forms synthetically in all tenses/aspects and moods (including participles and infinitives), or at least in all tenses/aspects/moods which are synthetic in the active voice. ${ }^{18}$ These appear to include the Blue Language, Bopal, Communicationssprache, Dil, Gilo, Kosmos, ${ }^{19}$ Langue international neo-latin, Lingua, Menet's lang. universelle, Mondlingvo, Mundolinco, Myrana, Olingo (hyphens), Oz, Pantos-Dimou-Glossa, Parla, Perio, Qosmiani, Unish, Veltparl, Volapük, Völkerverkehrsprache, Weltsprache (Eichhorn), and Weltsprache (Volk and Fuchs). One must be careful when including a language in this list, since there are some languages, both natural and artificial, which generally have synthetic passives, but which have a few forms which are analytic, i.e. one must look at the entire verbal paradigm. Some ALs have a passive marker which apparently is connected with a hyphen, e.g., Balta's oj- as in al oj-alog 'I am seen' (Couturat and Leau 1903/1979:19). It precedes the tense marker, e.g., $a$ - for the present tense, which is clearly a prefix, i.e., is not connected with a hyphen. In such cases one might wonder why only one of these types of markers is hyphenated.

${ }^{18}$ Of course one would only expect passives in all tenses/aspects and moods to be synthetic if all active forms were analytic. The significant question really is whether there are any analytic passive forms when the corresponding active forms are sythethic.

${ }^{19}$ It may be that Kosmos has some analytic passive forms as well (and analytic active forms), given the following remark by Couturat \& Leau (1903/1979:379): "One can use the verb esomi 'to be' with the participles of other verbs to render diverse nuances of the latter." 
There are many ALs, including the most widely used ones, which mainly have analytic passives, but again one must take care when classifying, since many ALs generally have analytic passives but have a few synthetic forms, usually or always participles and/or infinitives. There appear to be very few, if any, ALs whose passive forms are all analytic. One might think that all the passive forms of Interlingua (IALA) are analytic, given the following remark by Gode and Blair (1951:38):

The passive infinitives and participles are similarly composed of the infinitive and participles of the auxiliary with the past participle of the main verb following.
esser survelitate 'to be watched' essente surveliate 'being watched' essite surveliate 'been watched'

However, the past participle can occur alone as an adjective with a passive meaning, e.g., Le pluvia impellite per le vento entra trans le fenestra rumpite 'The rain driven by the wind comes in through the broken window' (ibid.:34), and so one could argue that not all the passive forms of the language are analytic. The same situation might hold in many or most other ALs which appear to have an entirely analytic passive system. One the other hand, it could be said that the words in question are not forms of the verb, but adjectives, and thus that all verb forms are analytic. Most of the passive forms of Zahlensprache are analytic, but the (present) infinitive and participles are synthetic; however, again one might claim that the participles are not verbal forms: Couturat and Leau label the passive participle forms which they give as nouns, adjective, and adverb.

Esperanto is a language which is mainly analytic in passive formation, but with possible exceptions: most passive forms consist of a form of esti 'to be' and a passive participle, e.g., Ili estis amataj 
130 Possibilities for Passives in Natural and Artificial Languages

de ciuj 'The were loved by all' (Wells 1969:10), but the passive participles themselves are synthetic, e.g., the present passive participle amata '(being) loved' (c.f., the present active participle amanta 'loving').

Some ALs have (mainly) analytic verbal systems, not only in the passive but also in the active. In at least some languages of this sort the passive could not be said to be more marked than the active or derived from it. As we shall see, the same is true for some languages with (mainly) synthetic passives. There are thus ALs in which both voices are (largely/mainly) synthetic, those where the active is (mainly) synthetic and the passive is (mainly) analytic, and those in which both voices are (mainly) analytic; however, we know of no ALs which have (mainly) synthetic passives and (mainly) analytic actives. In Hély's language all forms of all verbs, with the exception of ser and der, meaning 'to be' and 'to do' respectively, seem to be analytic, having as their first element the latter of these verbs in the active voice, and the former in the passive and neutral. ${ }^{20}$

Spokil has three ways of constructing passive forms, one synthetic and two analytic, a fact which becomes less surprising when we learn that there are two methods of forming active verbs, one synthetic and one analytic. Active tense/aspect/mood forms can involve affixes, e.g., arbai and arbei are present and past indicative forms of arbe 'to work', or they can consist of an infinitive followed by a word containing $l$ - and one or two tense/aspect/mood suffixes, e.g., arbe lai is another present indicative form of arbe. ${ }^{21}$ One can build a synthetic passive from a synthetic active form by means of -en-, which follows the root and precedes the tense/aspect/mood suffixes, e.g., movenai is a present passive indicative form of move 'love'. One kind of analytic passive is parallel in structure to the analytic active,

\footnotetext{
${ }^{20}$ This is one of a small number of ALs which have another possibility besides active and passive. Couturat and Leau (1907/1979:17) say of the neutral in Hély's language, "statifs, d'état" ("stative, of state").

${ }^{21}$ In fact there is a third way of constructing active forms in the secondary tenses.
} 
except that instead of the infinitive of the main verb there is the passive participle, e.g., moveno lai. The other analytic passive consists of a form of $v e$ 'to be' (which will bear the tense/aspect/mood marking) and then the passive participle, e.g., vai moveno.

Some ALs have both synthetic and analytic passives in at least some tenses, moods, etc. This is true of Europal, although one may get the impression from Weisbart's (1972:8) description that the synthetic forms have some sort of priority or are preferable: "The passive forms are formed by attaching the indicative endings to the present passive participle: $i$ salutadan 'I am greeted'. The forms iu san salutad are also permissible." (San is the present indicative of 'to be', $i$ is a shortened form of $i u$ 'I'.) Passive forms in Orba can be constructed with a form of the auxiliary ese 'to be' and the past participle. Orba also has a synthetic passive (at least of some tenses/aspects), formed by attaching tense/aspect/mood and person/number agreement markers as suffixes to the root. For example, the 1 st person present passive indicative of lemse 'to love' is ebo lemso or lemsobo.

There are both synthetic and analytic passives in Communia. Synthetic finite forms are marked by the suffix $-r$, placed at the end of active forms, e.g., the present and future active indicative forms of laudare 'to praise' are lauda and laudaro respectively, while their passive equivalents are laudar and laudaror. Passive infinitives are formed in a different manner: they end with $-i$ instead of the $-e$ ending of the active infinitives, e.g., laudari. Passive participles are also formed in a different way: compare the active and passive present participles laudant and laudandi, and the future active and passive participles laudaront and laudarondi. The analytic passive involves a form of esere 'to be' and a participle, probably the "absolute participle". 22

The order of the parts of analytic passives is generally for the

\footnotetext{
${ }^{22}$ Couturat \& Leau (1903/1979:411) say, "The author allows in addition an absolute participle ... which can be used in the active as in the passive ..."
} 
132 Possibilities for Passives in Natural and Artificial Languages

auxiliary verb to precede main verb form, as in most western European languages. However, in Unitario passives the main verb precedes the auxiliary, e.g., ego laudante estas, 'I am praised' (Pleyer 1990:105), "to set the passive apart from the other compound tenses" (ibid.); compare ego habas laudante 'I have praised' and ego sum studiendo 'I am studying' (ibid., OT).

In many natural languages with analytic passives, the main verb form does not need to be immediately after the auxiliary verb. The same possibility is explicitly permitted in American: "The passive voice is formed by using the verb, to be, as an auxiliary verb, with and before (though not necessarily the next word before) the perfect participle" (O'Connor 1917:16). Below is an example of a passive construction in American with the two parts separated.

$\begin{array}{lllll}\text { (42) ... Francián ůx } & 1 & \text { muć } & \text { dicedo } \\ \ldots \text {.. French } & \text { also is } & \text { extensively } & \text { spoken (ibid.:37) }\end{array}$

On the other hand this may not be allowed in Zahlensprache, if the following statement is accurate: "The passive is formed with the auxiliary verb sumum (to be), followed immediately by the infinitive from which one has cut off the final -m" (Couturat and Leau 1903/1979:101).

\subsection{Uniform and Non-uniform Passive Formation}

We have seen that some ALs are not uniform in their passive formation. Even among ALs that are entirely synthetic or analytic in this respect we find some which vary in how they make passive forms. We have already seen that in Communia synthetic passive infinitives and participles are marked differently than the other synthetic passive forms. Perio forms passives in three ways, depending on the tense/aspect/mood: in most cases $-t$ is added at or near the end of the active form; since the forms in question already have a $t$ in this 
position there will be a double or long $t t$, e.g., mi vidit 'I see', mi viditt 'I am seen'. The passive of the present infinitive, present participle, and past participle are built by attaching $-h$ to the end of the active form, e.g., vidi 'to see', vidih 'to be seen'. Unless there is an error in the able of verb forms in Couturat and Leau (1907/1979:6), the past passive infinitive is formed in yet another way, by the deletion of $t$ from the active equivalent: vidati is 'to have seen' while vidai is 'to have been seen'

Dil seems to be an AL which is entirely uniform in forming synthetic passives; the passive marker is always the suffix -i-, placed between the root and any other suffixes, e.g., loben 'to praise', lobien 'to be praised'; lobem 'praises (3SG INDIC)', lobiem 'is praised'.

There are also ALs which lack passives in some moods, etc. As far as we can determine, all passive forms in Hom-idyoma are part of the "[c]ompound conjugation with the passive participle in 'ata" (Cárdenas 1923:102) (with the exception of this participle itself), and Cárdenas (ibid.:104) states that this conjugation "has no imperative". Perhaps this should not be a surprise, since one cannot control what is done to one; it should be more surprising that so many languages, both natural and artificial, have passive imperatives. However, one might argue that passive imperatives are not to be interpreted literally: when one says, "be seen", what one means is "create a state of affairs such that you are seen' or something of the sort.

It is also theoretically possible for a language to have passive forms with no corresponding active forms. This seems to be the case for Idiom Neutral, which has a passive gerundive, e.g., amand 'who/which must be loved', but no active gerundive. (This is the same situation as in Latin.)

Another kind of non-uniformity involves verbal irregularity or different conjugations, i.e., where it is not different tenses, moods, etc. which show differences in passive formation, but where the choice of passive marking depends on the verb involved. However, such differences generally do not involve only the passive, i.e., if there are 
134 Possibilities for Passives in Natural and Artificial Languages

irregularities or more than one conjugation of verbs, they will show differences in tense, mood formation as well as passive formation. Therefore we shall not discuss this kind of variation here, with one type of exception, involving, one might say, the most radical difference possible: in some ALs, as in many (or most) natural languages, verbs can differ in whether they have passive forms at all. We believe that this would be common among ALs, but rarely is it explicitly stated that there are no passive forms of certain verbs perhaps it did not occur to some designers to state this e.g., for 'to be' even though they would not allow passive forms of it, or they did not think it necessary to state such a prohibition. Foulk (1937:37) is explicit about this in Americai Speak, saying, "Only verbs that take an object in the active voice have a passive voice" (our translation from Americai Speak). Concerning Esperanto Wennergren (2003: section "Pasivigeblaj frazoj") states "Only objective [i.e., transitive] verbs can be passivized". ${ }^{23}$

On the other hand, it would be striking if an AL has passive forms of e.g., 'to be'. According to Couturat \& Leau (1907/1979:7), the passive of sasi 'to be' in Perio is sasih 'to become'. However, one might question whether this is really a passive, or simply a form with passive morphology which does not have a passive meaning, unlike, e.g., (38b), which could be argued to be involve a passivized copular verb. ${ }^{24}$ In Weltsprache (Volk and Fuchs) the verb son 'to become'

${ }^{23}$ This is a prescriptive statement. For the vast majority of ALs there is not much need to distinguish between prescriptive and descriptive statements, since they saw so little use. Esperanto, as the most widely used AL is different in this regard. Consider what Wennergren (2003:ibid) later says: "Sometimes because of the influence of a national language the passivization of a completely intransitive verb can appear. Such sentences are to be avoided, because they go against the most basic principle of the passive". He then quotes a passage from a translation by Zamenhof from German into Esperanto which contains a passive of an instransitive verb and says "The sentence is bad, although by Zamenhof".

${ }^{24}$ In their chapter on Ulla Couturat \& Leau (1907/1979:92) give a form for the passive of este 'to be', este esten, but they do not comment on it and the second 
looks like the verb 'to be', san, with passive marking (i.e., the vowel $-o$ - instead of $-a-)$, but it is not described by Couturat and Leau (1903/1979:266-7) as the passive form of the latter.

\subsection{Deponent Verbs}

There are a fair number of ALs which are based partly or (almost) entirely on Latin. Given that such languages are generally attempts to simplify Latin, one might wonder whether deponent verbs, i.e. verbs with passive form and active meaning, have been eliminated in them. This is the case in Hély's language: Couturat \& Leau (1907/1979:18) state, "The deponents would be restored to the active form (confiter, or better confesser), as in the Romance languages". This also seems to be true of Kosmos, since Couturat and Leau (1903/1979:376) say, The deponent verbs of Latin are treated as if they had the active form (in -o). E.g.: imitomi, sequomi." Likewise in Linguum Islianum, "the deponent verbs are restored to the active form: imitare, mirare, ..." (ibid.:543). One the other hand, SPL has deponent verbs, although Dominicus (1982:87) says, "in SPL, the deponent verbs can be used either in their original passive form or in a simplified active form."

\subsection{Passivizable Positions in ALs}

One may wonder to what extent ALs allow promotion of indirect and prepositional objects; we have seen in section 2.2 that some natural languages allow this or an even wider range of clausal terms to be promoted. Foulk (1937:180) states that "A verb in the passive voice never has an object" (our translation from Americai Speak), which seems to rule out the passivization with a ditransitive verb. We

verb does not have the form one would expect, given that passive participles end in -ed, e.g., ested. We do not know whether this is an error. 
136 Possibilities for Passives in Natural and Artificial Languages

know of no clear examples of the promotion of an indirect object (or of any other constituent than a direct object) in any AL, and we know of no explicit statements that it is permitted, but this may be partly due to the fact that AL designers often do not discuss the syntax of their languages in great detail. Lojban seems to have (something like) the promotion of a wide range of positions, referred to as "conversion". However, this is said not to be passivization: "The effect is similar to what in English is called 'passive voice'. In Lojban, however, a conversion is not "passive"" (Nicholas \& Cowan 2003).

\subsection{Prefixes, Suffixes, and the Location of the Affix}

The location of the passive marking affixes relative to the root and to other affixes varies. A prefix is used for this purpose in Bopal, Gilo, Letellier's language, Lingua, Mondlingvo, Myrana (which also has an active prefix), Unish, and Volapük, while the passive of many languages involves a suffix, e.g., Dil, Menet's langue universelle, Mundolinco, Pantos-Dimou-Glossa, Parla, Uropa, and Veltparl. In Oz the passive marker, $-l-$, appears to be an infix: according to Elam (1932:9) it is placed "after the vowel of the stem as ep itQks yaf I see them; yaf itQlks ep they are seen by me." The letter $<Q>$ is this language stands for a vowel, and we take the root meaning 'see' to be Qks.

The order is passive-tense/aspect-root in Bopal (with the mood and person/number agreement markers being suffixes)(recall that this is also the order in Balta with its hyphenated passive marker). Myrana has the order person/number-voice-tense/aspect-root (with the mood markers again being suffixes). Unlike these languages, in Parla the passive marker, -et-, is adjacent to the root, e.g., labeti 'to be worked', labetai 'to have been worked' ( $-i$ and $-a$ - being the infinitive and past markers respectively). As we have mentioned, in Spokil synthetic passives also involve a suffix which is immediately after the root, and which precedes tense/aspect/mood markers. The Veltparl passive 
suffix goes immediately after the root, and thus is before the mood suffix, while the tense markers are prefixes. In Weltsprache (Eichhorn) the passive suffix is between the tense/aspect suffix and before the number agreement suffix (this language having number agreement but not person agreement). We thus see that AL designers have chosen a variety of different positions relative to other morphemes in the verb for their passive/voice affixes, sometimes before the root and sometimes after, sometimes closer to the root than other verbal affixes and sometimes further away than them.

\subsection{Choice of Auxiliary Verb}

Among languages which have analytic passives, there are differences in which auxiliary verb is used. We can draw a basic distinction between those languages which have an auxiliary whose only function is the formation of passives and those in which the auxiliary verb involved in passive formation has other functions. The former group is smaller. Arulo has the auxiliary verb verdar whose only function apparently is passive formation; it is followed by the present passive participle, which ends in -ata, e.g., el verdas vexata 'she is (being) teased' (Talmey 1925:12). ${ }^{25}$ The reason for this was apparently to prevent ambiguity. However, the verb 'to be' can be used for the same purpose: Talmey (ibid.:13) states, "Also esar may be used as auxiliary to form the passive, but verdar is preferable; ... li esos (verdos) defetata, they will be defeated." 26

According to Couturat \& Leau (1903/1979:207), in Dilpok "Le

\footnotetext{
${ }^{25}$ Arulo has a synthetic version of this, with verd- as a suffix, followed by a verbal ending, e.g., li punisverdis 'they were punished' (ibid.:13).

${ }^{26}$ Again there is a synthetic version, with es- suffixed to a participle from which the adjectival ending - $a$ has been removed, and followed by a verbal ending, e.g., Deo amatesas 'God is (being) loved' (ibid.:13). However, Talmey (ibid.:13) says that "This passive is not recommendable; it produces forms that are too long; reprezentatesabas, has been represented".
} 
138 Possibilities for Passives in Natural and Artificial Languages

passif se forme avec l'auxiliaire eri 'etre' et le participe passif: mi ere loved = je suis aimé". (The passive is formed with the auxiliary eri 'to be' and the passive participle: mi ere loved = I am loved".) However, there is another verb 'to be' in the language, esi, which is used as a copula, e.g., mi ese glad 'I am glad' (ibid.). This may indicate that ere is reserved for passive constructions.

INTAL has an auxiliary verb $f i$ which apparently only is used in passive forms, or more specifically in "the passive of the action" (Weferling 1974:13), ${ }^{27}$ which we would take to mean the true passive, while "the passive of the state" (ibid.) (i.e., we believe, the stative passive) involve es 'to be'. Weferling (ibid.) asserts that "It is absolutely necessary to distinguish [between the two types of passive] ... in the international language". ${ }^{28}$ The examples he gives (ibid.) are Me fi konvikat 'I become convinced', Le porte fi klozat cak vespre 'The door is closed every evening' (OT), and Le porte es klozat dum le tot nokte 'The door is closed through the whole night' (OT).

Among languages of the second type, i.e., in which there is no dedicated passive auxiliary, there are differences in the other functions of the passive auxiliary verb (c.f., English vs. German). Most languages of this type use 'to be' in passive forms (and presumably it is also used as a copula). Such languages include Americai Speak, Anglo-Franca, Dutton Speedwords, Internasionalo, Latino sine Flexione, Latinulus, Lingua Internacional, The Master Language, Nov Latin, Noviilatiin, Solresol, Spelin, Suma, and Zahlensprache. (Note that this fact is not surprising if an AL is (closely) based on English and/or a Romance language.) The passive forms of Universal-Latein involve the auxiliary fieri 'to become', e.g.,

\footnotetext{
${ }^{27}$ We have translated all quotations from this source from Weferling's original INTAL.

${ }^{28}$ Compare the remark in Gode and Blair (1951:38) concerning Interlingua (IALA): "Note that the passive as such cannot be distinguished from a form of esser 'to be' with a participial adjective. Io es maritate may mean 'I am being married' and 'I am being married."”
} 
fieram laudarate 'I am praised'. This is probably due to the influence of the designer's presumed native language, German.

\subsection{Choice of Main Verb Form}

ALs with analytic passives differ in which main verb form is used in passives. Many ALs, like many natural languages, use a perfect or past (active) participle as the form of the main verb, or to put it another way, the perfect/past active participle and the passive participle have the same form. These include American, Latino sine Flexione, Latinulus, Mundolingue, Nov Latin, and Novilatiin. Lingua Komun has an active and a passive participle. Couturat \& Leau (1903/1979:482), our source for this language, do not specify the tense/aspect of these, but they say, "the (anterior) composed tenses are formed by means of the auxiliary haver and the passive participle; the tenses of the passive, by means of the auxiliary eser and the same participle." Thus Lingua Komun represents the same situation, although described in a different manner in our source.

Apparently in contrast with these languages Antivolapük indicative (and some other?) passive forms involve an infinitive, e.g., io es aimer 'I am loved' (Couturat \& Leau 1903/1979:445). However, the infinitive is not a typical (Indo-European) infinitive in terms of its use: it also occurs in some active forms, e.g., io aver donner 'I have given' (ibid.), and for that matter, one could say, in active present forms, since e.g., io donner means 'I give'. Further, our source for Antivolapük, Couturat \& Leau (1903/1979), says nothing about participles in the language, so one could say that forms such as aimer function as both infinitives and participles and therefore that its passive is not really different from those of the languages just mentioned. The same situation seems to hold of Suma: there is only one synthetic form for verbs, which functions as an infinitive, indicative, main verb form in passive constructions, and main verb in past forms, e.g., ma oki mu 'I see him' (Russell 1966:2), ma te oki 'I 
140 Possibilities for Passives in Natural and Artificial Languages

am seen'.

Langue Catholique, on the other hand, can be more plausibly argued to have passives which use infinitive forms of the main verb (and this is how it is described by Couturat \& Leau (1903/1979:439-440)), since it has participles which are distinct from infinitives, as the former end in -ante and -ente. ${ }^{29}$ However, the infinitives are the same in form as finite verb forms, i.e. indicative, imperative, and subjunctive forms, e.g., ama is the imperfect active infinitive/indicative/subjunctive/imperative of 'to love'. The

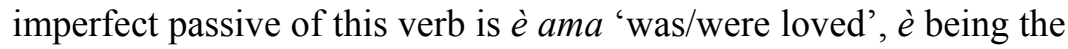
present tense of 'to be' ${ }^{30}$ In any case, the form involved is not a participle, so Langue Catholique does represent a different way of forming passives than many ALs (and natural languages) with analytic passive forms.

Faiguet de Villeneuve's Langue Nouvelle represents another possibility for constructing analytic passives: (a form identical to) the present active indicative is the form employed (after a form of sas 'to be'), e.g., the present passive indicative is sa dona 'am/are/is given', and in this language the present active indicative is different in form from the present infinitive: the former ends in - $a$, e.g., dona, the latter in -as, e.g., donas. ${ }^{31}$

It is only a minority of ALs with analytical passives which have a special form of the main verb which is used only as a passive participle (and not as a perfect participle and/or as some other form), just as it is a small minority of such languages which have a dedicated

\footnotetext{
${ }^{29}$ Alberto Liptay, the designer of Langue Catholique, "foresees two systems of conjugations" (Couturat \& Leau (ibid.:439); the description here may apply to only one of them.

${ }^{30}$ The form which Couturat \& Leau (ibid.:400) give for the present passive of this verb indicates that this form may be created in a different way: amè. (They say that this is "for ame-è").

${ }^{31}$ The 2nd person singular/plural imperative also has the same form as the present indicative (while the 1st and 3rd person imperatives have the same form as the present subjunctive).
} 
passive auxiliary. Dutton Speedwords is such a language: Dutton (1951:64-5) says:

It is a weakness of English construction-the same principle is also followed in certain other languages - that the endings '- $d$ ' and '-ed' are alike used $(a)$ to express the past tense of what are called weak verbs, and $(b)$ the passive voice ... In Speedwords a definite distinction is made, e.g., J yga 1 bu (past tense) ['I finished the book'], but L bu r e gad by Peter (passive voice, future tense) ['The book will be finished by Peter'], the passive voice indicator in Speedwords being the single-letter suffix $-d$. [..] The distinction is made because Speedwords are intended for the use of other nationals as well as the English-speaking peoples. Once this is achieved the present barriers to free international correspondence will be removed for all time.

As far as we can determine, in Spelin the form of the main verb used in passives, which ends in -ed, e.g., $i$ bi miled 'I am loved', is only used in the passive construction, even though Couturat \& Leau (1903/1979:474) called it "the past (passive participle)", and even though it apparently was derived from the English participle in -ed, which is the past participle and so has another function. We say this because the past and pluperfect forms in this language do not involve a form in -ed; in fact they are synthetic, e.g., mile 'has/have loved', mila 'had loved'. The main verb form used in passives is Zahlensprache apparently is distinct from all other verbal forms, since it is the infinitive (which also functions as the present indicative) without the latter's last segment: e.g., lamorem 'to love', sumum lamore 'to be loved'.

\subsection{Multiple Uses of Affixes}

Some ALs with synthetic passives are similar to some of the ALs 
142 Possibilities for Passives in Natural and Artificial Languages

discussed in sections 3.6 and 3.7 in that an element involved in passive formation also has another function, i.e., the passive affix can mark other categories.

In Gilo the prefix $a d$ - marks passive verb forms:

(43) a. Tom angez Peter. 'Tom angers Peter.'

b. Peter adagnez Tom. 'Peter is angered by Tom.'

(Giles 2000: sec. 7.1.1)

The same element is also a preposition, and marks agents, although it "is not required if the person/thing doing the action of the verb immediate[ly] follows the verb" (ibid.). This explains why it does not precede Tom in (43b) above; compare the sentences below:

$\begin{array}{llllll}\text { a. an piskis fata } & \text { ad-og-oz } & \mathrm{u} & \text { tri } \\ \text { one fish fat } & \text { PASS-give-PST to three } \\ \text { filis blaka ad du peil ajoma. } & \\ \text { cats white by two men old } & \end{array}$

'One fat fish was given to three black cats by two old men.'

b. an piskis fata u tri filis blaka adogoz du peil ajoma.

'One fat fish to three black cats was given by two old men.' (ibid.: Appendix A)

In (44a) we have both the prefix $a d$-and the preposition $a d$, but the latter does not need to occur in (44b), because again the agent phrase is adjacent to the verb. Apparently the prefix is not required in all passive sentences, given the following sentence:

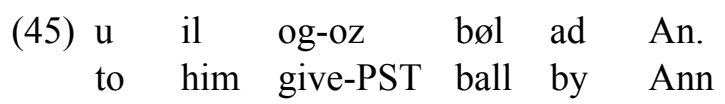


'To him was given the ball by Ann.' (ibid.: sec. 3.5.3) ${ }^{32}$

It is not clear to us why the prefix has been/can be left out, and perhaps this is a mistake on Giles' part; he says that "This form is 'grammatically correct' but its use is not recommended" (ibid.), although the absence of $a d$ - may not be the reason for this. $A d$ can also have an agentive type meaning for a phrase modifying a noun e.g., buk ad Dikenz 'a book by Dickens' (ibid.: sect. 7.1.1) (c.f., buk adritoz Dikenz 'a book written by Dickens' (ibid.)). ${ }^{33}$

The same general situation holds in Uhish: the passive marker is $b e-$, which as an independent word marks the agent of a passive, e.g., Buk beskribed be me 'The book was written by me' (Lee 2002:63).

The Uropa affix -ym- marks passive verb forms and objects. Donisthorpe (1913:21) gives the following explanation for this sharing of function:

It was explained in the Second Lesson that "ym" = "in relation to." Oma-vid e ym arba = the seeing-man is related to the tree; or, as we say, The man sees the tree: Oma vide arbam; ("arbam" = arba-ym). But if the seeing man is related to the tree, the tree must be related to the seeing-man. If "oma vide arba-ym," then "arba yme oma-vide," which may be written "arba vidyme oma," or as we say in English, "the tree is seen-by the man." It appears, then, that the root-idea in the "passive verb" is the root idea in the "objective noun." And, if the idea is the same, the same word should be used to express it. That word is "ym." "Ym" makes nouns objective (or "accusative") and it makes verbs objective (or

\footnotetext{
${ }^{32}$ Note that this sentence is a possible example of a passivized indirect object, although it is not entirely clear.

${ }^{33} A d$ is used to translate 'for' in the translation of "If as one people, speaking the same language, they have begun to do this, then nothing that they wish will be impossible for them": If, biz pei aga, piez po ama, uli ezgidioz ce, øka zafi fi uli wixuz buz oppos ad uli. (Giles 2000: Appendix C).
} 
144 Possibilities for Passives in Natural and Artificial Languages

"passive").

\subsection{The Markedness/Derivedness of the Passive}

As we have seen, in most natural languages, passives are more marked than actives. There are two ways in which this is manifested: in some languages a higher proportion of passive forms than of active forms are analytic and in some languages passive forms are derived from active forms by the addition of an affix. In ALs as well passives generally seem more marked than actives, and in the same two ways. However, there are some ALs in which one could not say that the passive is more marked than the active. We already mentioned the fact that in Hély's language both active and passive forms are analytic. In Mundolinco, as far as we can determine, all active and passive forms are synthetic, and passive forms contain the suffix $-r$. However, most active forms also have a suffix, $-s$, which occurs in the same position as $-r$ would, and so the passive apparently is not derived from the active, and so is not more marked than it. ${ }^{34}$ In Myrana, in most tenses/aspects both actives and passives (at least of most verbs) bear voice markers ( $t$ - for the former and $s h$ - for the latter ${ }^{35}$ ), e.g., the imperfect active indicative of punir 'to punish' is mitapun, while the corresponding passive is mishapun, so again the passive might not appear more marked that the active. However, in the present tense the active forms does not contain $t$ - (or the present tense marker $-e$-),

\footnotetext{
${ }^{34}$ The imperative, at least the form given in Couturat \& Leau (1907/1979:46), parlende, does not have the suffix $-s$. We do not know whether there are corresponding passive forms of it. One might speculate that it does not bear the active suffix since, as discussed above, strictly speaking a passive imperative is semantically odd, and perhaps lacking in this language, and so the designer of the language did not feel the need to give the active imperative forms the usual active marker, since there were no corresponding passive forms to be kept distinct from them.

${ }^{35}$ These voice markers are derived from the verbs tedje 'to do/make' and sheje 'to become'.
} 
while the passive forms still have $s h$-, e.g., the present active indicative of punir is mipun, and its passive counterpart is mishepun. Therefore one might claim that underlyingly in this language the active is more basic than the passive.

In Weltsprache (Volk \& Fuchs) the difference between active and passive forms is marked by the vowel of the final syllable: the former have $-a-$ or $-\ddot{a}-$, the latter $-o-$ or $-\ddot{o}-$. One could argue that in this language the passive is not more marked that the active.

\section{Recommendations}

First of all, we recommend that an AL have a passive. Although one might argue that an AL without one will be simpler, its existence gives a language more flexibility and more possibilities to express the subtle differences of meaning connected with thematic focus. As in other areas, the language designer may be caught between incompatible demands or desires, e.g., neutrality or internationality vs. recognizability. In terms of pure ease of learning, some of the choices we have discussed may not show a clear preference. Consider, for example the choice of synthetic vs. analytic passives. The major western European languages all have analytic passives and even Latin had some analytic passive forms. Does this mean that ALs, at least those whose potential speaker base would consist largely of those who have such a language as a mother tongue, should avoid synthetic passives? The answer is not clear to us, but we do not believe that synthetic passives would be unduly difficult to learn compared to an analytic passive, which may even be more difficult, given that one has to learn which two forms, e.g., which participle, is involved in their formation.

We would however recommend uniformity in passive formation: the passive forms of the AL should be either all synthetic or all analytic and we do not see any compelling reason to allow both 
146 Possibilities for Passives in Natural and Artificial Languages

synthetic and analytic passives, and in fact we wonder why some designers have done this; perhaps the reason is to permit stylistic variation. We think that there should be only one set of forms of the passive, all constructed in the same way (meaning with the same affix, if a synthetic passive is chosen), and that these forms should have precisely one function, that of marking the passive (e.g., they should not also mark middle or impersonal constructions).

We have seen that natural languages differ considerably in which positions they allow to be passivized. Here we would take a middle course, neither restricting passivization to direct objects nor allowing almost every NP in a sentence to become the subject of a passive. Although the latter choice would yield a wide variety of possibilities for thematic focus and stylistic variation, it could also produce many sentences which would be difficult for the majority of speakers to parse, given that most natural languages are not so free in this regard. We have found it difficult to make a principled decision about which positions should be passivizable: at least direct and indirect objects should be able to be promoted, as well as objects of prepositions if the preposition has undergone reanalysis to be joined to the verb and the objects of verb-particle constructions, e.g., John looked up the word $\rightarrow$ The word was looked up by John. Possibly all arguments should be passizivable, and the distinction between passivizable and non-passivizable positions should be along the lines of the argument vs. adjunct distinction. This option would lead to some sentences which were strange to some speakers, but the most striking and unusual instances of passivization from natural language would be ruled out.

Finally, we believe that the passive should be marked in relation to the active, i.e., if the language in question has a synthetic passive, that this passive should be constructed by adding an affix to the equivalent active form (rather than having affixes for both the active and the passive). The vast majority of natural languages have passive forms which can be said to be derived from active forms, and this may 
reflect some underlying notion that actives are more basic than passives, i.e., one might say, that the subject position (in nominative-accusative languages) is generally associated with agents and vice-versa. If this is the case, perhaps the marking of voices should reflect which one is felt to be basic or unmarked and which one is felt to be derived or marked.

\section{References}

Bartlett, P. 1998. Frater2. Available at URL $<$ http://www.smart.net/ bartlett/ frater2.html>.

Cárdenas, C. 1923. Hom-Idyomo (2nd edition). Leipzig: Fischer \& Wittig.

Comrie, B. 1988. Passive and Voice. In Shibatani (ed.), 1-23.

Couturat, L. \& L. Leau. 1903, 1907/1979. Histoire de la Language Universelle and Les Nouvelles Langues Internationales. Hildesheim: Georg Olms Verlag.

Dixon, R. 1977. A Grammar of Yidin. Cambridge: Cambridge University Press.

Dominicus, R. 1982. SPL. Wisconsin: Dominicus Publishing House.

Donisthorpe, W. 1913. Uropa. Guildford: W. Stent \& Sons.

Durie, M. 1988. The So-called Passive in Acehnese. Language 64, 104-13.

Dutton, R. 1951. Teach Yourself Dutton Speedwords. London: The English Universities Press.

Elam, C. 1932. The Case for an A Priori Language. Cincinnati, OH: The Open Sesame Press.

Foley, W. \& R. van Valin. 1984. Functional Syntax and Universal Grammar. Cambridge: Cambridge University Press.

Foulk, R. 1937. Americai Spek. New York: J. J. Little \& Ives.

Giles, A. 2000. Gilo Grammar. Available at URL <http://users.classicfm. net/alangiles/Grammar.htm>

Givón, T. 1979. On Understanding Grammar. New York: Academic Press (cited in Palmer 1994).

Gleitman, L. \& M. Liberman. 1995. The Cognitive Sciences of Language: Introduction. Language: An Invitation to Cognitive Sciences 1. Cambridge, MA: MIT Press.

Gode, A. \& H. Blair. 1951. Interlingua: A Grammar of the International 
148 Possibilities for Passives in Natural and Artificial Languages

Language. New York: Storm Publishers.

Haig, H. 1982. Passivization in Modern Western Armenian. In Hopper \& Thompson (eds.), 161-176 (cited in Palmer 1994).

Hashimoto, M. 1988. The Structure and Typology of the Chinese Passive Construction. In Shibatani (ed.), 329-354.

Haspelmath, M. 1990. The Grammaticalization of Passive Morphology. Studies in Language 14, 25-72.

Hopper, P. \& S. Thompson. (eds.). 1982. Studies in Transitivity. Syntax and

Semantics 15. New York: Academic Press (cited in Palmer 1994).

Huddleston, R. \& G. Pullum. 2002. The Cambridge Grammar of the English

Language. Cambridge: Cambridge University Press.

Jacobs, R. 1976. A Passive Continuum in Austronesian. Papers from the

Parasession on Diachronic Syntax 118-25. Chicago, IL: Chicago

Linguistics Society (cited in Shibatani 1985).

Jespersen, O. 1924. The Philosophy of Grammar. London \& New York: Allen \& Unwin.

Jones, L. 1972. Eurolengo. Newcastle upon Tyne: Oriel Press.

Keenan, E. 1972. Relative Clause Formation in Malagasy and Some Related and Some not so Related Languages. In Peranteau et al. (eds.), 169-189.

Keenan, E. 1985. Passive in the World's Languages. In Shopen (ed.), 243-81.

Kimenyi, A. 1988. Passiveness in Kinyarwanda. In Shibatani (ed.), 355-86.

Kozinsky, I., V. Nedjalkov, \& M. Polinskaya. 1988. Antipassive in Chuckchee: Oblique Object, Object Incorporation, Zero Object. In Shibatani (ed.), 651-706.

Kuno, S. 1973. The Structure of the Japanese Language. Cambridge, MA: MIT Press.

Lee, D.-Y. 2002. A Comparison of Unish Grammar with Esperanto. Journal of Universal Language 3.2, 57-74.

Libert, A. \& C. Moskovsky. 2002. On the Form and Function of Reflexives in Artificial Languages. Journal of Universal Language 3, 97-132. 2003. A Survey of Relative Pronouns and their Uses in Natural and Artificial Languages. Journal of Universal Language 4, 61-116.

Maslov, J. 1956. Očerk Bolgarskoj Grammatiki [Sketch of Bulgarian Grammar]. Moscow: Izdatel'stvo Literatury na Inostrannyx Jazykax.

Nedjalkov, V. \& S. Jaxontov. 1988. The Typology of Resultative Constructions. In Nedjalkov (ed.), 3-62.

Nedjalkov, V. (ed.). 1988. Typology of Resultative Constructions. 
Amsterdam: Benjamins.

Nicholas, N. \& J. Cowan. 2003. What is Lojban? The Logical Language Group. Available at URL <http://www.lojban.org/publications/level0/ brochure/book1.html>.

O'Connor, C. 1917. American: The New Pan-American Language. Buffalo, New York: Hansauer-Jones.

Palmer, F. 1994. Grammatical Roles and Relations. Cambridge: Cambridge University Press.

Peranteau, P., J. Levi, \& G. Phares. (eds.). 1972. The Chicago Which Hunt. Chicago, IL: Chicago Linguistics Society.

Pleyer, M. 1990. Unitario per Medio de Pictoroyn. Bensheim: Unitario Press.

Ringbom, H. 1987. The Role of the First Language in Foreign Language Learning. Clevedon: Multilingual Matters.

Rosenblum, B. 1935. Fitusa: Die Geburt einer Sprache. Self-pulbihsed, Basel.

Shibatani, P. (ed.). 1988. Passive and Voice. Amsterdam: Benjamins. 1985. Passives and Related Constructions. Language 61, 821-48.

Shopen, T. (ed.). 1985. Language Typology and Language Description. Cambridge: Cambridge University Press.

Siewerska, A. 1988. The Passive in Slavic. In Shibatani (ed.), 243-89.

Song, N. 1987. Empathy-based Affectedness and Passivization. Transactions of the Philological Society 1987, 74-89 (cited in Palmer 1994).

Talmey, M. 1925. Arulo: Text Book of the Universal Language. New York: Ilo Press.

Wald, M. 1909. Pan-kel (4th edition). Self-published, Gross-Beeren.

Weferling, E. 1974. Standard-Gramatika del International Auksiliari Lingue (6th edition). Self-published, Braunschweig.

Weisbart, J. 1972. Europal (Europäisch): Kurze Grammatik und Begrundung. Berlin: Michaelis \& Neumann.

Wennergren, B. 2003. PMEG: Plena Manlibro de Esperanta Gramatiko (version 12.2). Available at URL $<$ http://bertilow.com/pmeg/>.

Williams, M. 1989. Vygotsky's Social Theory of Mind. Harvard Educational Review 591, 108-126. 